\title{
The Experience of the Nurse Manager During the Middle East Respiratory Syndrome Epidemic
}

\author{
Sun $\mathrm{Ju} \mathrm{Kim}^{1}$ and In Sook Park ${ }^{2}$ \\ ${ }^{1}$ (Ph.D., NP) Chungnam National University Hospital, Korea \\ ${ }^{2}$ (Professor, Ph.D., Corresponding Author) College of Nursing, Chungnam National \\ University, Korea \\ 1akal0114@cnu.ac.kr, ${ }^{2}$ ispark@cnu.ac.kr
}

\begin{abstract}
The control role of nurse managers is very important in a crisis. To gain an in-depth understanding of the experiences of nurse managers during the MERS epidemic. Interviews were conducted with ten nurse managers who cared for patients with MERS. The interviews were transcribed and analyzed with content analysis. Nine categories were derived from 30 theme clusters: confusion from being exposed in an unprepared state; difficulty in managing as the infection became a disaster situation; anguish from being a nurse manager in the MERS outbreak; disappointment towards the views of colleagues and third parties; resentful of the family-oriented culture of Korea; gratification from leading the nurses by demonstrating their abilities as nurse managers; pride from the crisis coming to an end; gained confidence about their ability to manage a crisis, and sense of relief from policy changes and a broader perspective after the MERS epidemic. Nurse managers felt relieved that they were able to overcome the confusing crisis and make policy changes at the national level. Based on the findings, further research is needed to explore the crisis management leadership of nurse managers.
\end{abstract}

Keywords: Middle east respiratory syndrome (MERS), Nurse manager, Qualitative research, Experience

\section{Introduction}

Middle East Respiratory Syndrome (MERS) is a transmissible infectious disease that first occurred in Saudi Arabia in September 2012. It is a viral respiratory infectious disease that is transmitted by coronavirus [1]. In Korea, the first MERS patient was confirmed on May 20, 2015 , and the disease spread quickly to secondary patients in medical institutions. Until that first case, MERS was an unknown disease in Korea. The rapid spread of MERS created anxiety among Koreans, and people became even more anxious as they heard the news about the deaths of infected patients. It became a common practice for people to wear masks, while the number of school closings gradually increased. The spread of MERS not only had a socioeconomic impact, but it also had a broad impact on the daily life of individuals and

Article history:

Received (March 28, 2019), Review Result (April 27, 2019), Accepted (May 26, 2019) 
increased public fear [2][3]. The total number of MERS patients in Korea was 186, with a mortality rate of $20.4 \%$ [4].

The Korea Centers for Disease Control and Prevention (KCDC) implemented home isolation for people who were asymptomatic but had come into contact with patients who tested positive for MERS2. A total of 15 hospitals were placed under cohort isolation, which included nurses who provided care to MERS patients4. Among the nurses who provided care for suspected or confirmed MERS patients in four superior general hospitals, 43 nurses $(25.3 \%)$ were placed under isolation: $32(18.8 \%)$ were placed under home isolation, and 11 $(6.5 \%)$ were placed under in-hospital isolation [5].

Even under this crisis, nurses were working at hospitals out of their sense of ethical responsibility [6], but, at the same time, they were concerned about the spread of infection to themselves and those around them [7].

In the event of crises such as floods, earthquakes, and fires, as well as infectious diseases such as MERS, nurse managers participate in the overall situation while playing a major role in an interdisciplinary team [8][9][10].

According to reports, nurse managers in crises, including, for example, severe acute respiratory syndrome (SARS), must communicate clearly with nurses [11], assess the nurses' crisis coping skills and post-crisis management [12], and cooperate effectively with medical staff [13]. Fahlgren and Drenkard reported that nurse managers' critical responsibilities during an infection outbreak include planning disaster preparedness for public agencies and medical institutions, planning an open line of communication throughout the entire organization, training patients and staff, assembling an immediate response team, assisting nurses in providing proper patient care, playing the role of a coordinator while making effective decisions for cost-effective management, and protecting the nurses [13].

Moreover, nurse managers manage numerous challenges every day and take responsibility for the outcomes of administrative problems in a crisis [13], and they also play an important role in coordinating and effectively intervening in crises by closely supervising the processes and outcomes of quality of care and facilitating a health team consensus to improve the quality of patient care [14]. The leadership experience of managers can motivate the team to play an effective role, pay attention to the needs of workers, support physical and human resources, communicate with government officials, and provide emotional support by identifying psychological needs [15].

Moreover, Tzeng and Yin(2008) reported that during a crisis, nursing supervisors establish a crisis management system in nursing practice, help nurses comply with safety standards and respond appropriately, and participate in crisis management system policy-making and other medical institution activities [16]. Meanwhile, inadequate management by nurse managers during in-hospital crises may affect the quality of patient care and the spread of infection [17].

The MERS epidemic was a hospital crisis caused by an infectious disease, and the role of nurse managers was critical in this situation. Nevertheless, the search results with the keyword "MERS" revealed research on nurses and isolated persons, such as the turnover intention of cohort-isolated nurses in the MERS epidemic [4], post-traumatic stress factors [5], at-home isolation experience of contacted persons [2], the experience of nurses [18] and medical team [19]. However, research on the experience of nurse managers was hard to find.

The incidence rate of major disasters, such as earthquakes and typhoons, is gradually increasing. Such crises create situations where hospitals face an overflow of patients within a short period, and, since the outcomes may vary depending on the managers involved in such a crisis, the ability of managers to control the situation is important. Studies on the experience 
of managers under such crises are important; since quantitative studies on such experiences are limited, qualitative studies are needed.

Accordingly, the objective of this study is to understand the meaning behind the experiences of nurse managers during the MERS epidemic to gain a deeper understanding of the phenomenon. The research question for this objective is: What is the experience of nurse managers during the MERS epidemic?

\section{Methods}

\subsection{Participants}

The sample for the present study included 10 participants, including head nurses (emergency room, intensive care unit, and MERS unit), infection management team leaders, and nurse supervisors where suspected and confirmed MERS patients were hospitalized during the MERS epidemic.

\subsection{Data collections}

After obtaining approval from the Institutional Review Board of the author (201711-SB094-01), data collection was conducted through in-depth interviews using open-question and semi-structured question methods. The interviews were conducted after obtaining informed consent, and the interview was recorded. The interviews were conducted until the information reached a state of saturation where no new data would be available. The interviews were conducted once or twice for each participant, with each interview lasting about 1 hour. During the interview, a field note was used to record nonverbal expressions, and the recorded interview was immediately transcribed verbatim.

\subsection{Data analysis}

Data in the present study were analyzed using content analysis(Morse, 1995). Specifically, the analysis process involved the identification of meaningful words, phrases, and sentences from the collected data; the discovery of meaningful concepts and identification of the relationships between concepts; and the derivation of important and basic categories. During data collection and analysis, an effort was made to achieve bracketing to prevent researcher bias. First, the recorded interview was transcribed to identify the meaning of the overall content, and, while repeatedly listening to and reading the content, meaningful parts were underlined and conceptualized. Next, common characteristics of the conceptualized content were grouped into theme clusters, and similar theme clusters were combined into categories Confirmation was received from each participant on whether the written statement matched the statement given during the interview. Moreover, to determine whether the study results are appropriate for situations outside of the study setting and whether a third party reading the study results would find them to be meaningful and applicable based on his or her own experience, the study results were presented to a third party who was not a participant who agreed that the results were acceptable and agreeable. Other researchers and nursing scholars with plenty of experience in qualitative research were requested to read the study results to determine whether the themes for the study were properly derived and whether the derived meaning deviated based on which theme categorization was revised. 


\section{Results}

A total of 45 themes, 30 theme clusters, and 9 categories were derived from the in-depth interviews on the meaning and experience of nurse executives during the MERS epidemic [Table 1].

Table 1. Analysis of interviews with nursing managers through content analysis

\begin{tabular}{|c|c|c|}
\hline Themes & Theme clusters & Categories \\
\hline $\begin{array}{l}\text { Became a desperate emergency } \\
\text { Unfortunately that the national } \\
\text { quarantine system was breached }\end{array}$ & $\begin{array}{l}\text { Confusion due to the } \\
\text { unexpected admission of } \\
\text { MERS patients }\end{array}$ & $\begin{array}{l}\text { Confusion from being exposed } \\
\text { in an unprepared state }\end{array}$ \\
\hline $\begin{array}{l}\text { Widespread fear to the point of being } \\
\text { recognized as a disaster situation (quasi- } \\
\text { state of war) }\end{array}$ & $\begin{array}{l}\text { Spread of the MERS infection } \\
\text { leading to widespread fear }\end{array}$ & $\begin{array}{c}\text { Difficulty in managing as the } \\
\text { infection became a disaster } \\
\text { situation }\end{array}$ \\
\hline $\begin{array}{l}\text { Felt contempt and disappointment } \\
\text { towards nurses who protested the order } \\
\text { for dispatch work }\end{array}$ & $\begin{array}{c}\text { Disappointment in nurses who } \\
\text { protested the order for } \\
\text { dispatch work }\end{array}$ & \multirow{2}{*}{$\begin{array}{l}\text { Anguish from being a manager } \\
\text { of the MERS situation }\end{array}$} \\
\hline $\begin{array}{c}\text { Felt grateful to the nurses who } \\
\text { volunteered and accepted the dispatch } \\
\text { order }\end{array}$ & $\begin{array}{l}\text { Grateful to the nurses who } \\
\text { complied with the order for } \\
\text { dispatch work }\end{array}$ & \\
\hline $\begin{array}{l}\text { Disappointed with colleagues who } \\
\text { avoided me }\end{array}$ & $\begin{array}{l}\text { Disappointed with my nurse } \\
\text { colleagues who avoided me }\end{array}$ & $\begin{array}{c}\text { Disappointment towards the } \\
\text { views of colleagues and third } \\
\text { parties }\end{array}$ \\
\hline $\begin{array}{l}\text { Korean hospital visitation etiquette } \\
\text { exacerbated the spread of infection }\end{array}$ & $\begin{array}{l}\text { Resentful of the Korean } \\
\text { hospital visitation culture }\end{array}$ & $\begin{array}{l}\text { Resentful of the family-oriented } \\
\text { culture of Korea }\end{array}$ \\
\hline $\begin{array}{l}\text { Proud of being helpful as an executive in } \\
\text { the crisis to be managed well }\end{array}$ & $\begin{array}{l}\text { Proud of playing a part in } \\
\text { managing the crisis as an } \\
\text { executive }\end{array}$ & $\begin{array}{l}\text { Gratification from leading the } \\
\text { nurses by demonstrating their } \\
\text { abilities as a nurse executive }\end{array}$ \\
\hline $\begin{array}{l}\text { Stayed by the patients with a sense of } \\
\text { calling }\end{array}$ & $\begin{array}{l}\text { Proud of the sacrifices made } \\
\text { with a sense of calling }\end{array}$ & $\begin{array}{l}\text { Pride from the crisis coming to } \\
\text { an end }\end{array}$ \\
\hline $\begin{array}{l}\text { Gained confidence from the know-how } \\
\text { they obtained through experience }\end{array}$ & $\begin{array}{c}\text { Gained confidence about } \\
\text { being able to respond well to } \\
\text { the next crisis }\end{array}$ & $\begin{array}{l}\text { Gained confidence in their } \\
\text { ability to manage a crisis }\end{array}$ \\
\hline $\begin{array}{l}\text { Took interest in the world outside the } \\
\text { hospital and national agency system }\end{array}$ & $\begin{array}{l}\text { Observed more closely with a } \\
\text { broader view and perspective }\end{array}$ & $\begin{array}{c}\text { Sense of relief from policy } \\
\text { changes and a broader } \\
\text { perspective after the MERS } \\
\text { epidemic }\end{array}$ \\
\hline
\end{tabular}

\section{Conclusions}

The managers responded to the crisis while actively managing complex situations. As a result, the initial fear about the disaster situation was alleviated as the nurse managers gradually responded to the situation, and the situation eventually came to an end. In the meantime, the nurse managers were able to gain confidence in their ability to manage crises. Based on in-depth interviews with nurse managers, 45 themes, 30 theme clusters, and 9 categories were derived. Based on these results, it was determined that the nurse managers were proud of themselves for successfully performing their duties as nurse managers in a crisis, and they overcame a confusing situation. Moreover, they also felt relieved that policy changes on a national level were being implemented. The findings in the present study can be used as basic data in the development of competency-based leadership training programs for crises. In addition, future studies on crisis management leadership are recommended. 


\section{Acknowledgments}

We thank the 10 participants for their generous contributions.

\section{References}

[1] Khan M.U., Ahmad A, Fatokun O., and Shah S., "Knowledge and attitude of healthcare workers about the middle east respiratory syndrome in multispecialty hospitals of Qassim," Saudi Arabia, BMC Public Health, vol.14, no.1, (2014)

[2] Choi J.S. and Kim J.S., "Factors influencing preventive behavior against Middle East Respiratory SyndromeCoronavirus among nursing students in South Korea," Nurse Education Today, vol.40, pp.168-172, (2016)

[3] Ha J.Y. and Ban S.H., "Home isolation experience of the people exposed to Middle East Respiratory Syndrome positive patients," Journal of Qualitative Research, vol.18, no.1, pp.34-48, (2017)

[4] Korea Centers for Disease C, "Prevention. The Middle East Respiratory Syndrome Coronavirus Outbreak in the Republic of Korea," Osong Public Health and Research Perspectives, vol.6, no.4, pp.269-278, (2015)

[5] Heeja J, Aelee C, Gunjeong L, Jiyoung K, and Sunyoung J., "Turnover intention of nurses that were cohort quarantined during the Middle East Respiratory Syndrome(MERS) outbreak," Journal of the Korea Academia-Industrial Cooperation Society, vol.18, no.3, pp.175-184, (2017)

[6] Kim H.J. and Park H.R., "Factors affecting post-traumatic stress of general hospital nurses after the epidemic of Middle East Respiratory Syndrome infection,” Journal of Korean Clinical Nursing Research, vol.23, no.2, pp.179-188, (2017)

[7] Khalid IdiycTJQMR, "Healthcare workers emotions, perceived stressors and coping strategies during a MERS-CoV outbreak," Clinical Medicine \& Research, vol.14, no.1, pp.7, (2016)

[8] McMullan C, Brown GD, and O'Sullivan D., "Preparing to respond: Irish nurses' perceptions of preparedness for an influenza pandemic,” International Emergency Nursing, vol.26, pp.3-7, (2016)

[9] Hsin-Chao Tseng, Thai-Form Chen, and S-MCsnet, "SARS: Key factors in crisis management," Journal of Nursing Research (Taiwan Nurses Association), vol.13, no.1, pp.58, (2005)

[10] Livornese K. and Vedder J., "The emotional well-being of nurses and nurse leaders in crisis," Nurs Adm Q., vol.41, no.2, pp.144-150, (2017)

[11] Fahlgren T.L. and Drenkard K.N., "Healthcare system disaster preparedness, part 2: Nursing executive role in leadership,” Journal of Nursing Administration, vol.32, no.10, pp.531-537, (2002)

[12] Shih F.J., Turale S., Lin Y.S., et al., "Surviving a life-threatening crisis: Taiwan's nurse leaders' reflections and difficulties fighting the SARS epidemic," Journal of Clinical Nursing, vol.18, no.24, pp.3391-3400, (2009)

[13] Peltz R., Shushan O., Nakash G., et al., "Disaster healthcare system management and crisis intervention leadership in Thailand-lessons learned from the 2004 tsunami disaster," Prehospital and Disaster Medicine, vol.21, no.5, pp.299-302, (2006)

[14] Tzeng H.M. and Yin C.Y., "Crisis management systems: staff nurses demand more support from their supervisors," Appl Nurs, vol.21, no.3, pp.131-138, (2008)

[15] Chen S.L., Chen K.L., Lee L.H., and Yang C.I., "Working in a danger zone: A qualitative study of Taiwanese nurses' work experiences in a negative pressure isolation ward," American Journal of Infection Control, vol.44, no.7, pp.809-814, (2016)

[16] Rattanakanlaya K., Sukonthasarn A., Wangsrikhun S., and Chanprasit C., "A survey of flood disaster preparedness among hospitals in the central region of Thailand," Australasian Emergency Nursing Journal, vol.19 no.4, pp.191-197, (2016)

[17] Basu M., Ghosh S., Jana A., Bandyopadhyay S, and Singh R., "Resource mapping during a natural disaster: A case study on the 2015 Nepal earthquake,” International Journal of Disaster Risk Reduction, vol.24, pp.24-31, (2017) 
[18] Bongiovanni I., Leo E., Ritrovato M., Santoro A., and Derrico P., "Implementation of best practices for emergency response and recovery at a large hospital: A fire emergency case study," Safety Science, vol.96, pp.121-131, (2017)

[19] Mashreky S.R., Rahman A., Khan T.F., Faruque M., Svanström L., and Rahman F., "Hospital burden of road traffic injury: Major concern in primary and secondary level hospitals in Bangladesh," Public Health, vol.124, no.4, pp.185-189, (2010)

\section{Authors}

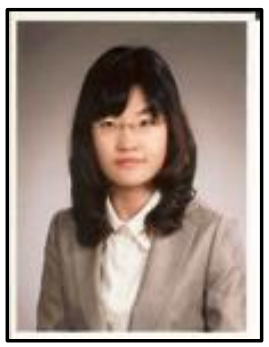

\section{Sun Ju Kim}

Ph.D. College of Nursing, Chungnam National University NP, The Ministry of Health and Welfare (MOHW) NCLEX-RN, New York

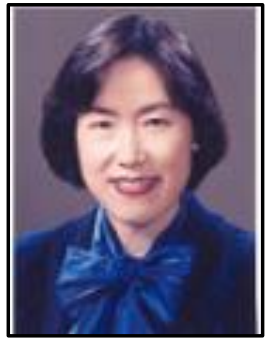

\section{In Sook Park}

Professor, Ph.D., Corresponding Author, College of Nursing, Chungnam National University 